\title{
New Concepts in Mood Stabilization: Evidence for the Effectiveness of Valproate and Lamotrigine
}

\author{
Charles L. Bowden, M.D.
}

Recognition of limited overall benefits from lithium in bipolar disorder, with even greater disadvantages in more severe forms of the disease, has spurred interest in alternative therapies. A long history of development of evidence for the utility of valproate has culminated in welldesigned, placebo-controlled studies that establish the efficacy of the divalproex form of valproate in acute mania. Generally positive, but as yet not conclusive, studies indicate continued benefits in prophylactic treatment of bipolar disorder. The spectrum of efficacy of valproate is somewhat broader than that of lithium, extending to patients with certain more severe forms of the illness; e.g., mixed manics. Pretreatment plasma GABA activity was positively correlated with magnitude of improvement in manic symptomatology with divalproex. The evidence of comparable clinical benefits for lithium and valproate has stimulated studies that indicate overlapping effects on specific $G$ protein-linked signal transduction for lithium and valproate, but not for carbamazepine. The possibility that additional antiepileptic drugs might have efficacy in bipolar disorder has encouraged early clinical studies with several newer antiepileptic drugs. Preliminary evidence for the efficacy of one of these, lamotrigine, has been presented.

[Neuropsychopharmacology 19:194-199, 1998]

(C) 1998 American College of Neuropsychopharmacology. Published by Elsevier Science Inc.
KEY WORDS: Valproate; Lamotrigine; Bipolar disorder; Manic-depressive

The definition of the term mood stabilizer has been largely unaddressed. A proposed working definition is a drug that alleviates the frequency and/or intensity of manic, hypomanic, depressive, or mixed episodes in patients with bipolar disorder, and that does not increase frequency or severity of any of the types of bipolar disorder episodes (Bowden 1996). This article presents the evidence that valproate is an effective mood stabilizer and the much more preliminary evidence that lamotrigine may also be a mood stabilizer.

From the University of Texas Health Science Center at San Antonio, Department of Psychiatry, San Antonio, Texas, USA.

Address correspondence and reprint requests to: Dr. C. L. Bowden, The University of Texas Health Science Center, Department of Psychiatry, 7703 Floyd Curl Drive, San Antonio, TX 78284-7792, USA.

Received February 23, 1998; accepted February 23, 1998.
Lithium has been the only mood stabilizer widely employed for bipolar disorder since its approval by the FDA in 1970. Gradual recognition of substantial limitations in the efficacy and safety of lithium has contributed to interest in alternative treatments for bipolar disorder. The evidence for the limited efficacy of lithium has been reviewed elsewhere. Even among patients who did adhere to lithium treatment, improvement was often partial, both regarding severity and frequency of episodes (Goldberg et al. 1995; Maj et al. 1989). Of some importance, the evidence is not that lithium is moderately but generally effective. Rather, the data consistently indicate groups of patients with quite good responses, but other groups with no improvement or actual worsening with lithium treatment (Bowden et al. 1994; Small et al. 1991). Patients with good response include those with pure, or classical, manic episodes, (Prien et al. 1988; Secunda et al. 1985) patients with three or fewer lifetime illness episodes (Gelenberg et al. 
1989), and patients with relatively mild forms of bipolar disorder (Grof et al. 1993). Previous response or nonresponse to lithium is highly correlated with response in a new manic episode (Bowden et al. 1994).

Conversely, patients with rapid-cycling illness courses, more severe manic symptoms, mania secondary to neurological and other medical conditions, and mixed mania do relatively poorly (Grof et al. 1993; Himmelhoch and Garfinkel 1986). These are not modest but large differences in response. For example, in mixed mania, response rates to lithium are from one-third to one-half the response rates observed in purely manic patients (Secunda et al. 1985; Prien et al. 1988; Bowden 1995).

Regardless of benefit, many patients have adverse effects from lithium that seriously interfere with function, often at serum levels close to that needed for symptomatic benefit. The adverse effects of lithium fall into two categories. Mild, but quite common, adverse effects of tremor, skin rashes, gastrointestinal disturbances, renal concentrating impairment, weight gain, and cognitive impairment contribute to the high frequency of poor compliance to lithium (Shaw et al. 1986; Gitlin et al. 1989; Harrow et al. 1990). Less common adverse effects of hypothyroidism, neurological toxicity, and renal parenchymal damage may severely interfere with function. Both groups of adverse effects occur at serum concentrations of lithium at or only slightly higher than needed for clinical benefits.

Impelled by recognition of some of these limitations of lithium, the search for alternatives to lithium was active even before regulatory approval of lithium. The first such drug reported effective was valporate in a 1966 publication of Lambert (Lambert et al. 1966). Studies of carbamazepine followed shortly thereafter. Valproate has been the subject of the most systematic investigation of treatment efficacy in bipolar disorder in recent years. Numerous other medications have been studied, but with results that have been negative (e.g., clonidine), at best equivocal (e.g., verapamil), or of limited benefit but inferior to lithium (e.g., neuroleptics) (Janicak et al. 1989; Janicak et al. 1993b). The development of evidence for the effectiveness of valproate, carbamazepine, and, potentially certain other antiepileptic compounds is of interest, because it has been clinician driven, with minimal programmatic or financial support either from industry or federal health science agencies. For example, the consistently positive open and partially controlled reports of valproate were uniformly conducted without extramural support. Only in the past 6 to 8 years has there been some support from research pharmaceutical companies.

\section{Valproate}

Two randomized, placebo-controlled, parallel group studies have established the efficacy of the divalproex form of valproate in acute mania. The studies had similar methodologies, requiring that patients had a full manic episode, did not have concurrent substance abuse or secondary mania, did require hospitalization, and did not receive neuroleptics, and did receive only modestly, tightly defined amounts of lorazepam for insomnia/agitation. The demographic and illness severity characteristics of the patients in both studies are quite similar to patients studied in other clinical trials in mania in recent years (Bowden et al. 1995). The Pope et al. (1991) study was of a small number of patients at one center, was limited to patients judged nonresponsive to lithium, and did not include women of child-bearing potential. The Bowden et al. study was larger in scope, was conducted at eight academic medical centers led by investigators with experience in bipolar disorder, did include women of child-bearing potential, and did include a lithium-treatment group. The study is the only randomized, parallel group study on lithium in acutely manic patients ever conducted (Bowden et al. 1994). Both studies found divalproex highly statistically significant superior to placebo. Improvement was evident by the end of the first week of the 3-week trials and was associated with patients obtaining trough serum levels of valproate of $45 \mu \mathrm{g} / \mathrm{ml}$ or greater (Bowden et al. 1996).

The Bowden et al. study allowed secondary analyses, which have further clarified features associated with response. Patients with mixed mania who were treated with lithium had significantly poorer responses than mixed manic patients who were treated with divalproex, or than pure manic patients treated with lithium (Bowden 1995). The response of pure manic patients did not differ significantly between divalproex- and lithium-treated patients. Patients with psychotic symptoms had greater improvement with divalproex treatment than lithium treatment. Response among divalproex-treated patients was unrelated to history of response to lithium during previous manic episodes. The study, therefore, provides strong evidence for the effectiveness of both lithium and divalproex in acute mania, with evidence suggestive of a broader spectrum of effectiveness for divalproex. Divalproex was better tolerated than lithium, (Table 1) both in terms of the percentage of patients prematurely discontinued for intolerance and in relationship to specific adverse effects.

Additional open trials suggest effectiveness of divalproex in those subtypes of bipolar disorder for which lithium is relatively ineffective. Most of these studies lacked randomization or concurrent comparator treatments, thus the results are suggestive, not conclusive. The most consistent results are of conditions which, symptomatically, are characterized by irritable, mixed mania. These include positive results in acutely manic adolescents (Papatheodorou and Kutcher 1993), mania secondary to neurological conditions (Tohen et al. 
Table 1. Comparative Adverse Effects of Divalproex Sodium and Lothium in Acute Mania for Adverse Events at Least Twice as Frequent as for Placebo

\begin{tabular}{lcc}
\hline Adverse Event & $\begin{array}{c}\text { Divalproex Sodium } \\
(\boldsymbol{n}=\mathbf{6 9 )} \mathbf{( \% )}\end{array}$ & $\begin{array}{c}\text { Lithium } \\
(\boldsymbol{n}=\mathbf{3 6}) \mathbf{( \% )}\end{array}$ \\
\hline Asthenia & 13 & 19 \\
Constipation & 10 & 17 \\
Dizziness & 16 & 8 \\
Fever & 1 & 14 \\
Nausea & 23 & 31 \\
Twitching & 3 & 8 \\
Vomiting & 14 & 25 \\
\hline
\end{tabular}

Bowden et al. (1994).

1990), and mania co-occurring with alcoholism (Brady and Sonne 1995). Although a full review is beyond the scope of this article, three studies provide consistent evidence that mixed mania is characterized by hypercortisolism; whereas, pure mania is not (Swann et al. 1986; Evans and Nemeroff 1983; Krishnan et al. 1983). The possibility of identification of biological differentiators to aid both in diagnosis of subtypes of such bipolar disorder as mixed mania and prediction of treatment response to specific drugs is of great interest.

Although a full elucidation of the pharmacological mechanism of valproate as an antimanic and mood-stabilizing agent is not available, two lines of evidence are of interest, both regarding potential insights into the pathophysiology of the disorder and control points for mood stabilization drugs. Higher pretreatment plasma GABA levels were correlated positively with amount of improvement in manic syndrome in the Bowden et al. (1994) study (Petty et al. 1995). Valproate caused a significant decrease in plasma GABA, which was unrelated to magnitude of clinical improvement. By contrast, response to lithium was unrelated to GABA levels, and GABA did not change with lithium treatment. These data are consistent with preclinical studies and studies in epilepsy, which suggest that some aspects of valproate's actions are through GABA systems.

The second line of inquiry, addressed in other articles in this issue, indicates that chronic valproate administration at therapeutically relevant concentrations has effects on intracellular signaling systems quite similar to those of lithium. Both lithium and valproate significantly reduced protein kinase C (PKC) and G protein activity, with specificity for alpha and epsilon moieties (Manji and Potter 1997). Both also reduced myristolated alanine-rich C kinase substrate (MARCKS) protein, which is linked to $G$ protein signal transduction, and conveys some cytoskeletal integrity to neuronal membranes (Lenox et al. 1992). Both selectively enhance DNA binding activity of the transcription factor known as activator binding protein (Bowden 1997). The onset of these actions seems to occur earlier with valproate than with lithium, which is possibly relevant to the corresponding evidence for a somewhat earlier onset of clinical activity. These several signaling actions did not occur with carbamazepine.

Maintenance-phase studies of bipolar disorder are inherently more difficult to conduct and analyze because of the multiple types of clinical episodes possible and the difficulty in limiting medications to one drug. Open and randomized studies of valproate report consistently positive results. No placebo-controlled data are available, although a 1-year placebo-controlled maintenance-phase study has recently been completed. Two well-designed studies warrant more detailed discussion. Calabrese and Delucchi studied bipolar patients with rapid-cycling illness courses and reported high rates of sustained response for 1 year in both mixed an pure manic patient. Approximately half of patients received divalproex as monotherapy, and half in combination with lithium, with equivalent response in the two groups (Calabrese and Delucchi 1990). Lambert and Venaud reported results of a randomized, open comparison of valproate versus lithium for an 18month period (Lambert and Venaud 1995). Efficacy, as assessed by number of new illness episodes, was comparable, but somewhat more favorable in the valproatetreated patients. Valproate was better tolerated than lithium. Patients who failed to respond satisfactorily to the drug to which randomized could be crossed over to the alternative treatment. The subsequent response, in terms of patients changed from initial lithium to valproate, was more favorable than among patients changed from initial valproate to lithium.

The principal acute benefits of lithium, divalproex, and carbamazepine seem to be on manic, rather than depressive, episodes (Lambert and Venaud 1995). As with much maintenance-phase study, the evidence for the relative efficacy of lithium, valproate, and carbamazepine regarding prophylaxis against new episodes is scant. The previously described work by Lambert is perhaps the best work published as of this date.

Because valproate has been commercially available since the mid-1960s, the amount and quality of data regarding safety and adverse effects are exceptional for a newly approved drug. Valproate has minimal effects on organ systems other than the central nervous system, gastrointestinal tract, hematological system, liver, and pancreas. Cognitive effects are favorable as compared to carbamazepine and lithium. Therefore, the drug is an appealing candidate in many conditions wherein cognitive capacity is already diminished (e.g., dementia, mental retardation, organic mental disorders), or the patient expects to function at a peak intellectual level (bipolar spectrum disorders), or mild dysphoria increases the likelihood of poor adherence to the treatment regimen (substance use disorders). The therapeutic index of safety is greater than for lithium or 
carbamazepine. Thus, risks, including that of overdose, are less with valproate. This is particularly important, because the disorders for which valproate seems to be helpful are associated with increased risk of suicide (e.g., bipolar disorder, other recurrent mood disorders, panic disorder) and impulsivity (e.g., alcoholism, impulse control disorders, bipolar disorders).

The relatively favorable adverse effect profile of valproate has contributed to interest in studying its effectiveness in a variety of conditions with unstable moods. These are sometimes referred to collectively as bipolar spectrum disorders. Among several interesting such conditions, impulsive aggression has had the largest number of published reports. This dimensional, as opposed to syndromal construct, is characterized by manic-type agitation, irritability, impulsivity, and hostility. Studies have spanned the age spectrum from youth to old age. Many such patients have neurological deficits resulting from mental retardation, brain trauma, stroke, and dementia, thus reducing their tolerance for lithium. Over ten studies have reported consistent efficacy of valproate in such patients, usually at doses and serum levels observed in efficaciously treated patients with bipolar disorder (Bowden 1997; McFarland et al. 1990). Only in those patients with dementia have doses and serum levels been somewhat lower than the 45 to $110 \mu \mathrm{g} / \mathrm{ml}$ range reported as effective and well tolerated in acutely manic patients (Bowden et al. 1996).

\section{Carbamazepine}

Studies of carbamazepine have been more difficult to interpret, principally because of methodological problems. Most studies have allowed substantial use of other medications, including neuroleptics. Patients enrolled in studies have often been diagnostically heterogeneous (Janicak et al. 1993a). No randomized, placebocontrolled studies have been published. The one placebo-controlled trial published was of 19 patients crossed over to placebo, and indicated a better response to carbamazepine than to placebo (Post et al. 1984). Comparisons with lithium suggest somewhat lesser efficacy for carbamazepine in acutely manic patients (Lerer et al. 1987; Small et al. 1991; Denicoff et al. 1995).

The characteristics of patients likely to respond to carbamazepine are also less clearly established. One study indicates that patients with secondary mania responded better to carbamazepine that to lithium (Himmelhoch and Garfinkel 1986). Patients with rapid-cycling bipolar disorder seem to respond less well than patients without rapid cycling (Okuma et al. 1990).

\section{Lamotrigine}

Recognition that properties of some, although not all, antiepileptic drugs may be usefully harnessed for con- trol of bipolar symptomatology has heightened interest in assessing newer antiepileptic compounds for possible antimanic or mood-stabilizing properties. The early experience with lamotrigine, described in detail elsewhere in this issue, is of particular relevance. Lamotrigine is a drug recently approved for use in epilepsy in over 70 countries. Its mechanism of action includes an effect not shared by other antiepileptic or mood-stabilizing drugs, inhibition of sodium channel activity subsequently linked to glutamate activation, but limited to the use-dependent, not resting sodium channel activity (Grunze et al. 1966). Additionally, use-dependent inhibition of calcium channel activity may occur (Goa et al. 1993). An open trial of lamotrigine, taken both as monotherapy and in combination with other mood-stabilizing antidepressant drugs indicates both acute episode and maintenance benefits in bipolar disorder (Calabrese et al. 1995). Of interest, both patients with initial mania and depressive episodes improved clinically.

Currently approved antidepressants have been little studied in bipolar depressed patients. All seem to pose some risks for inducing mania and hypomanic episodes and for causing more mood instability, although this issue is in need of further study. Thus, it is of interest to determine whether lamotrigine provides antidepressant benefits without inducing mania or increased cycling frequency.

\section{CONCLUSION}

The available data, particularly data derived from two well-designed and executed studies of Pope et al. (1991) and Bowden et al. (1994), indicate that divalproex is effective in the acute treatment of mania, comparable to lithium in overall efficacy, has a faster onset of action than that achieved with lithium (particularly if an oral loading dose strategy is employed), and is generally better tolerated than lithium. The margin of safety in conditions of an overdose is greater for divalproex than for lithium. Studies that are not conclusive, but are consistently positive, suggest that divalproex may be substantially more effective than lithium for several subtypes of bipolar disorder that generally are regarded as difficult to treat.

In contrast, the scant data for lamotrigine are at present of greater heuristic than practical clinical importance. They do suggest broad and well-tolerated effectiveness, with, in contrast to lithium and valproate, greater effectiveness on depressive episodes. This general interest in antiepileptic drugs with putative moodstabilizing properties increases the likelihood that additional new drugs will be systematically assessed for the efficacy and safety in the treatment of bipolar disorder over the next decade. 


\section{REFERENCES}

Bowden CL, Brugger AM, Swann AC, Calabrese JR, Janicak PG, Petty F, Dilsaver SC, Davis JM, Rush AJ, Small JG, Garza-Trevino ES, Risch SC, Goodnick PJ, Morris DD (1994): Efficacy of divalproex vs. lithium and placebo in the treatment of mania. JAMA 271:918-924

Bowden CL (1995): Predictors of response to divalproex and lithium. J Clin Psychiat 56:25-30

Bowden CL, Calabrese JR, Wallin BA, Swann AC, McElroy SL, Risch SC, Hirschfeld RMA (1995): Who enters therapeutic trials? Illness characteristics of patients in clinical drug studies of mania. Psychopharmacol Bull 31:103109

Bowden CL (1997): Treatment of bipolar disorder. Current Review of Mood \& Anxiety Disorders 1:167-176

Bowden CL, Janicak PG, Orsulak P, Swann AC, Davis JM, Calabrese JR, Goodnick P, Small JG, Rush AJ, Kimmel SE, Risch SC, Morris DD (1996): Relation of serum valproate concentration to response in mania. Am J Psychiat 153:765-770

Bowden CL (1997): Toward an integrated biological model of bipolar disorder. In Joffe R, Young LT (eds), Bipolar Disorder: Biological Models and Their Clinical Applications. New York, Marcel Dekker, Inc, pp 235-254

Brady KT, Sonne SC (1995): The relationship between substance abuse and bipolar disorder. J Clin Psychiat 56:19-24

Calabrese JR, Woyshville MJ, Bowden CL, Rhodes L, McElroy S, Keck P, Cookson J, Kundu S, Andersen J, Ascher J, Bolden-Watson C, Paterson G (1995): "Spectrum of efficacy" of lamotrigine in treatment-refractory manic depression. Paper presented at the 2nd international conference on new directions in affective disorders in Jerusalem

Calabrese JR, Delucchi GA (1990): Spectrum of efficacy of valproate in 55 patients with rapid-cycling bipolar disorder. Am J Psychiat 147:431-434

Denicoff KD, Smith-Jackson E, Disney E, Syed AO, Leverich GS, Post RM (1995): Carbamazepine, lithium, and the combination: A bipolar maintenance trial. Proc Am Psychiat Ass, 178

Evans DA, Nemeroff CB (1983): The dexamethasone suppression test in mixed bipolar disorder. Am J Psychiat 140:615-617

Gelenberg AJ, Kane JM, Keller MB, Lavori P, Rosenbaum JF, Cole K, Lavelle J (1989): Comparison of standard and low-serum levels of lithium for maintenance treatment of bipolar disorder. N Engl J Med 321:1489-1493

Gitlin MJ, Cochran SD, Jamison KR (1989): Maintenance lithium treatment: Side effects and compliance. J Clin Psychiatr 50:127-131

Goa KL, Ross SR, Chrisp P (1993): Lamotrigine: A review of its pharmacological properties and clinical efficacy in epilepsy. Drugs 46:152-176

Goldberg JF, Harrow M, Grossman LS (1995): Course and outcome in bipolar affective disorder. Am J Psychiat 152:379-384

Grof P, Alda M, Grof E, Fox D, Cameron P (1993): The challenge of predicting response to stabilizing lithium treat- ment. The importance of patient selection. Br J Psychiat 163(S):16-19

Grunze H, Wegerer JV, Walden J (1966): Lamotrigine may limit pathological excitation by modulating calcium and potassium currents. Eur Neuropsychopharmacol 6:S4S155

Harrow M, Goldberg JF, Grossman LS, Meltzer HY (1990): Outcome in manic disorders: A naturalistic follow-up study. Arch Gen Psychiat 47:665-671

Himmelhoch JM, Garfinkel ME (1986): Sources of lithium resistance in mixed mania. Psychopharmacol Bull 22: 613-620

Janicak PG, Sharma RP, Easton M, Comaty JE, Davis JM (1989): A double-blind, placebo-controlled trial of clonidine in the treatment of acute mania. Psychopharmacol Bull 25:243-245

Janicak PG, Davis JM, Preskorn SH, Ayd TJ (1993a): Principles and Practice of Psychopharmacotherapy. Baltimore, Williams \& Wilkins, pp 351-353

Janicak PG, Sharma R, Peterson J, Leach A, Davis JM (1993b): A double-blind, placebo-controlled trial of verapamil for acute mania: Preliminary results. ACNP Abstracts of Panels and Posters 245 (abstract)

Krishnan RR, Maltbie AA, Davidson JR (1983): Abnormal cortisol suppression in bipolar patients with simultaneous manic and depressive symptoms. Am J Psychiat 140:203-205

Lambert PA, Cavaz G, Borselli S, Carrel S (1966): Action neuropsychotrope d'un nouvel anti-épileplique: Le Dépamide. Ann Med Psychol 1:707-710

Lambert PA, Venaud G (1995): Comparative study of valpromide versus lithium as prophylactic treatment in affective disorders. Nervure, Journal de Psychiatrie 7:1-9

Lenox RH, Watson DB, Patel J, Ellis J (1992): Chronic lithium administration alters a prominent PKC substrate in rat hippocampus. Brain Res 570:333-340

Lerer B, Moore N, Meyendorff E, Cho SR, Gershon S (1987): Carbamazepine versus lithium in mania: A doubleblind study. J Clin Psychiat 48:89-93

Maj M, Priozzi R, Kemali D (1989): Long-term outcome of lithium prophylaxis in patients initially classified as complete responders. Psychopharmacology 98:535-538

Manji HK, Potter WZ (1997): Monoaminergic systems. In Joffe R, Young LT (eds), Bipolar Disorder: Biological Models and their Clinical Application. New York, Marcel Dekker, Inc., pp 1-40

McFarland BH, Miller MR, Straumfjord AA (1990): Valproate use in the older manic patient. J Clin Psychiat 51:479-481

Okuma T, Yamashita I, Takahashi R, Itoh H, Otsuki S, Wantanabe S, Sarai K, Hazama H, Inanaga K (1990): Comparison of the antimanic efficacy of carbamazepine and lithium carbonate by double-blind controlled study. Pharmacopysychiatry 23:143-150

Papatheodorou G, Kutcher SP (1993): Divalproex sodium treatment in late adolescent and young adult acute mania. Psychopharmacol Bull 29:213-219

Petty F, Rush AJ, Davis JM, Calabrese JR, Small JG, Swann AE, Kramer GL, Orsulak PJ, Blake M, Bowden CL (1995): Plasma GABA predicts response to divalproex in mania. Biolog Psychiat 37:593-683 
Pope HG, Jr, McElroy SL, Keck PE Jr, Hudson JI (1991): Valproate in the treatment of acute mania: A placebo-controlled study. Arch Gen Psychiat 48:62-68

Post RM, Uhde TW, Ballenger JC (1984): The efficacy of carbamazepine in affective illness. Adv Biochem Psychopharmacol 39:421-437

Prien RF, Himmelhoch JM, Kupfer DJ (1988): Treatment of mixed mania. J Aff Dis 15:9-15

Secunda S, Katz MM, Swann A, Koslow SH, Maas JW, Chuang S, Croughan J (1985) Mania: Diagnosis, state measurement, and prediction of treatment response. J Aff Dis 8:113-121

Shaw ED, Mann JJ, Stokes PE, Manevitz AZ (1986): Effects of lithium carbonate on associative productivity and idiosyncrasy in bipolar outpatients. Am J Psychiat 143:1166-1169

Small JG, Klapper MH, Milstein V, Kellams JJ, Miller MJ, Marhenke JD, Small IF (1991): Carbamazepine compared with lithium in the treatment of mania. Arch Gen Psychiat 48:915-921

Swann AC, Secunda SK, Katz MM, Koslow SH, Maas JW, Chang S, Robins E (1986): Lithium treatment of mania: Clinical characteristics, specificity of symptom change, and outcome. Psychiat Res 18:127-141

Tohen M, Watemaux CM, Tsuang MT, Hunt AT (1990): Four-year follow-up of twenty-four first-episode manic patients. J Aff Dis 19:76-86 